\title{
SENTIMENTOS DE ADOLESCENTES QUE SE SUBMETERAM AO ABORTAMENTO PROVOCADO
}

\author{
Deise Rigo' \\ Valeska Marchetti Pin ${ }^{2}$ \\ Eleonor Moretti ${ }^{3}$
}

Resumo: Este estudo possibilitou o desvelamento dos sentimentos de adolescentes que se submeteram ao abortamento provocado, dos motivos que influenciaram na sua decisão de interromper a gravidez e das formas de indução do abortamento. Isso foi possível através de estudo exploratório-descritivo de abordagem qualitativa, em que foram entrevistadas adolescentes que compareceram à emergência de um hospital geral de grande porte da região do Planalto do Rio Grande do Sul, no período de julho a outubro de 2000. 0s dados foram coletados através de entrevistas e anotações de campo. Como resultados, encontraram-se os seguintes dados:1) os sentimentos encontrados foram:

\footnotetext{
'Acadêmica do IX Nivel do curso de Enfermagem, pesquisa realizada como requisito da disciplina de Iniciação Científica I e II e Métodos Quantitativos e Qualitativos.

Endereço: Marechal Floriano, n 349. Centro. Erechim - RS. CEP: 99700-000

${ }^{2}$ Acadêmica do IX Nivel do curso de Enfermagem, pesquisa realizada como requisito da disciplina de Iniciação Cientifica I e II e Métodos Quantitativos e Qualitativos.

Endereço: Senador Alberto Pasqualini, n 665. Centro. Guaporé - RS. CEP: 99200-000 ${ }^{3}$ Orientadora. Mestre em Enfermagem. Professora Titular III das disciplinas de Saúde da Mulher I e II do Curso de Enfermagem da Universidade de Passo Fundo.

Endereço: Capitão Eleutério, 510/apto. 201. Centro - Passo Fundo - RS. CEP: 99010 - 062 
tristeza, depressão, desespero, alivio, liberdade, dor do pecado, pavor, medo de humilhações e vergonha; 2) os motivos que levaram ao abortamento: a idade, a familia, a falta de preparo para assumir uma gestação e, posteriormente, uma criança, a instabilidade no relacionamento, as condições socioeconômicas e a desinformação sobre métodos contraceptivos; 3) os métodos utilizados para provocar o abortamento foram: chás, sondas e Cytotec (methotrexate). Em vista disso, recomenda-se aos profissionais da área que reflitam sobre a prática de suas atividades quanto à educação sexual e à assistência por eles prestada em âmbito hospitalar, devendo ser realizadas de novas pesquisas para que esses assuntos sejam aprofundados.

Palavras Chaves: Adolescência, Gravidez, Aborto, Sentimentos

\section{INTRODUÇÃO}

A adolescência é uma fase de transição, em que tudo se altera em um espaço muito curto de tempo. É uma fase marcada pela aventura de cada descoberta, pelo surgimento da sexualidade, pelas mudanças do corpo, que se torna desconhecido e, especialmente, acarreta para a menina o assumir de um novo papel: o de mulher. Por conseqüência, as relações consigo mesma, com a família, com outros adolescentes e com o meio em que vive sofrem mutações.

Os pais também sofrem com essas mudanças, pois, nessa fase de amadurecimento sexual, temem pelos riscos a que seus filhos possam se expor. A questão sexual ainda é, nos dias de hoje, um assunto muito difícil de ser abordado entre pais e filhos, com pouco avanço entre as gerações, como afirma Gurgel, citado por Fonseca (1996,p. 12): "Se antigamente os pais quase não conversavam sobre sexo com os filhos devido à repressão sexual, hoje continuam falando pouco e um dos principais motivos é o tempo curto para o diálogo e a convivência”, o que resulta em desinformação sexual de crianças e jovens.

Com freqüência, as adolescentes não vinculam a prática sexual à probabilidade de uma gravidez; geralmente desconhecem os métodos 
contraceptivos ou a forma correta de utilizá-los; as relações sexuais, geralmente são esporádicas e imprevisíveis; ainda, na maior parte das vezes, o parceiro também é adolescente e, portanto, desinformado sobre a prática sexual e suas conseqüências.

Essa falta de informação faz com que aumente o número de gravidezes precoces e indesejadas na adolescência. A ocorrência de gravidez em meninas de 10 a 19 anos é cada vez maior e atinge as camadas de nivel socioeconômico menos favorecidas, nas quais a expectativa de êxito para os jovens é muito reduzida.

A gravidez não desejada tem efeitos físicos, psicológicos e sociais. Começa com a angústia e dúvidas sobre o fato de estar grávida, continua com a decisão traumática de abortar e completa-se com o ambiente sinistro onde é realizado o abortamento no Brasil, especialmente para quem não é rico. Além disso, a adolescente já é discriminada como mulher e, em caso de uma gravidez, isso se acentua com pressões geradas pela família, pelo parceiro e pela sociedade.

Nas familias de classe social menos privilegiada, a gravidez no período da adolescência é mais facilmente aceitável, devido a uma conjuntura socioeconômica, cultural e política diferenciada. Já, nas classes média e média-alta, as mulheres deixam para casar e ter filhos bem mais tarde, pois antes querem se realizar profissional e financeiramente para, só depois, pensar em maternidade.

Na prática, a gravidez indesejada tem apenas duas soluções: "abortar" ou “assumir". Ambos os caminhos podem gerar sofrimento e conflitos, pois se a adolescente abortar (provavelmente será um abortamento provocado e por meio de técnicas impróprias), corre sérios riscos, tanto em sua saúde física como na mental; já, se decidir assumir, haverá o risco de se ter mais uma criança rejeitada e maltratada.

Outros fatores predisponentes para uma gestação indesejada na adolescência são:

- a insuficiência de ações para educação sexual de crianças e adolescentes;

- a falta de orientação por parte dos pais e, até mesmo, 
Enquanto alunas do curso de Enfermagem, observaram-se todos os problemas descritos e, acima de tudo, teve-se oportunidade de entrar em contato com adolescentes que passaram ou passam por gravidezes indesejadas, com outras que já provocaram abortamento e com profissionais da área da saúde. Foi possivel, através desses contatos, concluir que as relações sexuais estão iniciando cada vez mais cedo entre as adolescentes; conseqüentemente, a gravidez indesejada acontece antecipadamente na vida dessas jovens. Muitas vezes sem alternativas, só lhes resta recorrerem ao abortamento, já que se encontram em um estado de aflição, discriminação e desamparo.

Em vista disso e considerando que o conhecimento e a compreensão dos sentimentos podem contribuir para a qualificação da assistência integral de enfermagem e a prevenção do abortamento na adolescência, realizou-se este estudo, cujo objetivo geral é conhecer os sentimentos das adolescentes sobre o abortamento provocado. Como objetivos especificos têm-se: a) conhecer os motivos que influenciam a decisão das adolescentes de interromperem a gravidez; b) identificar as formas de indução de aborto utilizadas pelas adolescentes; c) divulgar nos serviços de saúde os resultados da pesquisa a fim de contribuir para a melhoria da assistência às adolescentes evitando-se, assim, novos casos de abortamento.

\section{PRESSUPOSTOS}

A partir da literatura revisada e pelas experiências vivenciadas como acadêmicas, levantaram-se os seguintes pressupostos:

a) muitas adolescentes engravidam pela falta de informações sobre os métodos contraceptivos, vindo, mais tarde, a provocar o abortamento;

b) grande parte das adolescentes abortam por pressão social ou da família e, muitas vezes, por falta de apoio dessas; 
c) outras causas que influenciam na decisão de provocar abortamento são os fatores socioeconômicos;

d) somente quando aparecem complicações severas, as adolescentes que abortam procuram ajuda médica em hospitais.

\section{METODOLOGIA}

0 estudo exploratório-descritivo de abordagem qualitativa foi realizado com seis adolescentes entre 10 e 19 anos, residentes em municipios do Planalto Médio do Rio Grande do Sul, as quais se submeteram ao abortamento provocado.

Os dados foram coletados pelas pesquisadoras no periodo de julho a outubro de 2000, no setor de emergência de um hospital geral de grande porte do município de Passo Fundo, na residência de uma das adolescentes e em locais previamente acordados entre as pesquisadoras e as adolescentes, com o intuito de assegurar a privacidade, $\mathrm{o}$ anonimato e a confidencialidade da entrevista. As participantes foram incluidas no estudo mediante os seguintes critérios: terem entre 10 e 19 anos de idade; estarem em processo de abortamento provocado ao chegar ao setor de emergência ou com história de abortamento provocado há, no máximo, dois meses e consentirem em participar do estudo.

Utilizou-se como técnica de coleta de dados a entrevista semiestruturada, realizada com um roteiro-guia, contendo dados de identificação e questões relacionadas aos sentimentos das adolescentes em relação ao abortamento, seus motivos para a interrupção da gestação e as formas de indução de aborto. 0 número de participantes no estudo foi determinado pela saturação de dados.

0 trabalho foi precedido da autorização formal da instituição e consentimento livre e esclarecido da adolescente, o qual assegurava o anonimato, privacidade, confidencialidade, liberdade de desistência sem represálias e de acesso aos dados do relatório. Foi acordado previamente com cada uma das adolescentes a permissão ou não para a gravação das entrevistas em fita cassete havendo apenas uma recusa. Essa mesma 
adolescente recusou-se também a assinar o termo de consentimento, porém aceitou participar do estudo. Para o registro das informações, as adolescentes foram identificadas por codinomes de flores.

As entrevistas foram transcritas imediatamente após a sua realização, destruindo-se as fitas utilizadas na gravação. Para analisar os dados, utilizou-se a análise temática proposta por Minayo (1994, p.208), observando as seguintes etapas:

1a) Pré-análise:

Consiste na organização do material transcrito com leitura e releitura exaustiva do mesmo e constituição do corpus, atendendo aos critérios de exaustividade, representatividade, homogeneidade e pertinência. Nessa etapa, foram determinadas as unidades de registro, utilizando-se palavras-chave.

2a) Exploração do material:

Os textos, recortados em unidades de registro, foram agrupados para estabelecer as categorias temáticas.

3) Tratamento dos resultados obtidos e interpretação:

Por último, procedeu-se à interpretação dos dados à luz do referencial teórico e dos pressupostos do estudo.

\section{ANÁLISE DE DADOS}

\subsection{Expressando os temas}

Sentimentos expressos pelas adolescentes durante o processo de abortamento:

Os sentimentos relacionados ao abortamento e expressos pelas adolescentes durante todo o processo permitiram a sua apresentação em quatro temas:

\subsubsection{O sofrimento: da decisão à ação}

0 sentimento mais evidenciado nas falas das adolescentes entrevistadas 
foi o sofrimento, desvelado a partir da situação de desespero, depressão e tristeza enfrentado desde a descoberta da gravidez até sua interrupção, como se pode constatar nas falas abaixo:

...quando chegou dia 30, nada de vir...fiquei no desespero...ai fiz um teste de farmácia e deu positivo...entrei em desespero...não posso nem me lembrar...eu não quis passar por nenhuma humilhação...já estava completamente deprimida com a situação...

(Palma) ...agora eu tô bem, já passou o pior...eu tô triste, não queria ele agora, mas já que veio...

(Flor de lis)

Depressão é o sentimento de estar esquisito, infeliz, melancólico, na fossa... a depressão ocorre quando a raiva fica recolhida e voltada para o interior de nós mesmos... quando as pessoas ficam tristes por muito tempo, sem compreender o que é que sua mágoa significa, perdem contato, freqüentemente com o acontecimento que causou a tristeza. 0 resultado é a depressão... a pessoa deprimida parece atormentada, desesperada para refrear sua raiva e o ódio que sente por si mesma...na depressão, a pessoa tem o senso de ter perdido alguma coisa de muito importante, da qual - anteriormente - ela não era consciente... (VISCOTT, p. 109, 1982).

...Podem-se...distribuir parcelas de culpa a todos. O que não se pode, entretanto, é culpar o feto, o único condenado à morte, no final das contas. Essa constatação, consciente ou inconsciente, pesa no psiquismo da adolescente, que desenvolve intensa sensação de culpa, quase sempre somada à depressão, que vai acompanhála por toda a vida. Não é incomum que, mais tarde, essas mulheres tenham dificuldades de formação de vinculos emocionais $e$ desenvolvam disfunções sexuais (RIBEIRO, p. 108, 1999).

Também estão presentes entre os sentimentos vivenciados o pavor e o medo de praticar o abortamento, pois as jovens se preocupavam com complicações no seu estado de saúde, com o fato de se sentirem sós num momento de decisão tão importante. Vejam-se extratos das suas falas a respeito:

...sempre menstruei certo e ficava durante quatro dias, e agora, passou duas semanas e nada de vir e eu comecei a desconfiar, daí 
eu procurei o pai da criança e ele me disse que era casado e que se eu tivesse grávida teria que tirar...eu me apavorei...contei só para minha prima para ela me ajudar...eu não sabia o que fazer...

(Onze-horas)

...achei que fosse mais dificil se livrar da gravidez...espero ficar bem...que não dê nenhum problema sério comigo...fiquei com medo de fazer o aborto...

Com referência ao depoimento transcrito, Viscott (p. 47, 1982) interpreta o medo como forma de autoproteção; assim, ignorá-lo põe em perigo, resultante de um desejo forte ou sobre a verdade dos sentimentos. 0 medo chama a atenção para uma possível ameaça ao bem-estar da pessoa. Para as adolescentes deste estudo, engravidar e abortar são situações que focam o direito de reproduzir-se ou não. Vivenciadas precocemente, essas questões desencadeiam sofrimento, que, na gravidez, mostra-se mais acentuado por força de um estado indesejado, que clama por uma decisão de curto prazo. Desesperada, a adolescente debate-se com a pressão social, o medo e o pavor de uma intervenção de risco, geralmente realizada em locais inapropriados.

Em situações como essa, Felipe (p. 147, 1995) defende o direito de as mulheres decidirem "sobre quando, como e, quantas vezes vai permitir que processos gerativos desencadeados em seu corpo sejam preservados até seu término, em especial quando ela se encontra em uma condição de abandono, seja material, emocional, afetivo ou sexual".

\subsubsection{A autopreservação de julgamentos sociais:}

0 sentimento de se autopreservar em relação ao meio em que vive, relatado pelas adolescentes, está diretamente ligado com a vergonha de decidirem interromper a gravidez.

A partir do relato de Palma, citado anteriormente, percebe-se que o medo de passar por uma humilhação fez com que ela provocasse o abortamento como forma de auto-preservação dos julgamentos sociais. 
Palma relata o medo de ser julgada pela sociedade, a qual é à favor do desenvolvimento de uma gestação. Do ponto de vista social, a falta de aceitação formal do abortamento exclui a mulher que aborta e a faz sentir-se marginalizada.

Perante a sociedade, Palma não possuía as condições ideais para levar adiante a gravidez e assumir a situação, pois ainda está nova demais para a maternidade; sua situação socioeconômica não era favorável e, acima de tudo, o parceiro não assumira a paternidade, o que significa que esta adolescente seria "mãe solteira".

Sobre o depoimento de Palma, encontra-se na literatura a observação de Paula (p. 27, 1996), que registra:

Os motivos apontados pela mulher para praticar o aborto, relacionavam-se ao medo da rejeição familiar e à questão social: mãe solteira, em cidade interiorana, cheia de preconceitos sociais e morais.

\subsubsection{0 remorço de ter pecado}

Os sentimentos ligados a crenças religiosas são citados poucas vezes, contudo, quando aparecem, geralmente são expostos como um temor a Deus, por terem "matado" seu próprio bebê, terem violentado seu corpo e ido contra os propósitos exigidos por determinadas crenças.

...é um pecado a gente fazer uma coisa dessas ... chorei ... chorei ... chorei bastante ... eu fiquei com vergonha ...

(Jasmim)

Segundo Willke (p. 64, 1980 ): “É certo que há sentimento de culpa advindo de crença religiosa, mas na maioria dos casos, o sentimento de culpa que se segue a um aborto, pouco tem a ver com determinada crença religiosa. 0 problema é que o aborto é sempre uma violência que está na base da natureza de uma mulher, o normal é que ela seja doadora da vida “.

\subsubsection{A liberdade para seguir vivendo:}

Outro sentimento também relatado pelas adolescentes foi o de alívio e 
...o cara era casado e tinha 36 anos...ele me disse que se eu tivesse grávida eu teria que tirar...

(Onze-horas)

...eu tenho já duas meninas e dai o meu marido ficou brabo...o meu marido não queria... a gente não tinha como criar..

(Jasmim)

Muitas vezes, as adolescentes se submetem ao abortamento provocado pela falta de compromisso entre ela e o pai da criança ou por acharem que o parceiro não seria o pai ideal para seu filho. Existem ainda as adolescentes que já têm filhos e são casadas, mas, devido ao fato de o marido não aceitar mais uma criança motivou-as à interrupção da gravidez. Nessa linha, Paula (p. 39, 1996) descreve o relato de uma cliente da seguinte forma: "0 namorado, em hipótese alguma, assumiria a paternidade e determinara o aborto, como condição para continuidade do namoro". Pinotti (p. 2,1988), refere que "nem sempre o parceiro e a mãe são um apoio. A maior parte do tempo a mulher grávida sente que todo o peso da situação está sobre seus ombros e que não recebe nenhuma ajuda da sociedade."

Conforme Alan Gutt Macher Institute (p. 25, 1994), “ a relação da mulher com o companheiro é instável e não tem a constância suficiente para que o casal considere ter e criar filhos juntos, ou o homem retirou seu apoio emocional e econômico quando tomou conhecimento da gravidez." Essa pressão torna-se tão intensa que a adolescente (que já vive em um conflito de idéias e decisões) opta pelo abortamento sem ter outra opção.

4.2.3 A instabilidade financeira associada ao abortamento As condições socioeconômicas inadequadas são outro fator determinante na hora de decidir entre a gravidez e o abortamento, como se pode observar nos relatos a seguir:

...ganho pouco...não era hora agora...

(Flor de lis)

...e dai não dava... a gente não tinha como criar... 
A falta de dinheiro leva muitas adolescentes a optarem pelo abortamento devido às despesas geradas por uma gravidez, e consequentemente, ao nascimento da criança.

Segundo Alan Gutt Macher Institute (p. 25,1994), “ a adolescente provoca o abortamento pois não pode arcar com os custos de ter e criar um filho porque ela, ou seu companheiro, ganha pouco, trabalha em emprego de tempo parcial ou está desempregada."

Referindo-se as condições socioeconômicas, Moretti et al. (p. 16, 1998), relatou:

“ a mulher não pode arcar com os custos de ter e criar um filho porque ela, ou seu companheiro, ganham pouco, trabalha em emprego de tempo parcial, está desempregada ou estuda."

4.2.4 Desinformação sobre métodos contraceptivos e a falta de seu conhecimento

Um dos motivos que indiretamente influenciaram as adolescentes ao abortamento foi a desinformação quanto aos métodos contraceptivos: ...eu não tomava remédio...e ele falou que ia tirar na hora de gozar e eu acreditei, eu era virgem...nunca imaginei que fosse engravidar...agora eu já sei como evitar a gravidez...

(Onze-horas)

Muitos fatores afastam os casais da prática do planejamento familiar, como, por exemplo, a falta de conhecimento de métodos contraceptivos ou a ruptura do acordo em relação ao ato sexual. Geralmente, os casais não se protegem, pois depositam uma certa “confiança” entre si. Contudo, em virtude dos serviços de saúde, uma nova conscientização está surgindo, com ênfase na promoção da saúde, através da autoprevenção, em que não está em jogo o tipo de relacionamento, mas, sim, a finalidade de cuidados essenciais para evitar uma gravidez indesejada. 


\subsection{Os métodos mais utilizados na indução do abortamento}

Os métodos mais utilizados no processo de abortamento foram o Cytotec (methotrexate - MTX), chás e introdução de sondas no útero, constatados nas seguintes falas:

...eu comprei um remédio (Cytotec) na farmácia do tio da minha amiga...tomei dois comprimidos e coloquei mais dois...

(Palma) ...chá de canela durante três dias,...e depois de duas semanas começou dores no fundo da barriga e cólicas com sangramento, permaneceu durante 14 dias...

(Tulipa)

...eu coloquei uma sonda...saiu muito sangue, eu tinha dor e cólica...

(Onze horas)

Os métodos utilizados pelas adolescentes para provocar o abortamento, conforme os depoimentos, foram bastante variados. Uma marca fundamental foi a preocupação com o resultado final, pois muitas estavam inseguras quanto aos riscos que corriam com a utilização desses métodos. 0 uso da sonda, introduzida no útero, por exemplo, pode causar sérios danos à saúde da mulher, pois há o risco de perfuração do útero, hemorragias, infecções e, quando utilizada com substâncias ácidas e/ou tóxicas, pode causar danos muito maiores.

Os chás também podem levar à intoxicação e hemorragias, assim como a utilização do Cytotec, seja por via oral ou vaginal, o qual provoca a contração da musculatura uterina até a expulsão do feto; porém, se acaso isso não ocorrer, há o risco de o bebê nascer com má formação congênita. Segundo Alan Gutt Macher Institute (p.15, 1994),os métodos mais referidos pelas adolescentes utilizados para induzir o abortamento são:

- a aplicação vaginal ou oral da droga chamada methotraxate (Cytotec), que é autorizada para o tratamento de úlceras gástricas e duodenais; faz os músculos uterinos se contrairem, o que costuma provocar sangramento e a expulsão parcial ou completa dos conteúdos do útero;

- a administração oral de soluções de ervas; 
- a injeção ou ingestão de produtos hormonais;

- a introdução de sondas ;

- técnicas que vão de exercícios pesados à repetição de saltos e quedas.

\section{CONSIDERAÇÕES FINAIS}

Este estudo tornou possível não só identificar os sentimentos das adolescentes que se submeteram ao abortamento provocado como também conhecer os motivos que influenciaram na sua decisão de interromper a gravidez e suas conseqüências, identificando as formas de indução de aborto utilizadas.

Ressalta-se a necessidade de perceber cada adolescente como um ser único, singular e que, passando pela mesma situação, apresenta variados sentimentos em relação ao abortamento, entre eles: medo, pavor, desespero, vergonha, depressão, tristeza, dor do pecado, alivio e liberdade, relatados através de depoimentos. Esses sentimentos estão diretamente ligados à realidade de cada uma das entrevistadas.

Vale ressaltar também os motivos que levaram as adolescentes a provocar o abortamento como forma de acabar com um certo problema vivenciado por elas. Pôde-se perceber, no momento da entrevista, motivos relacionados à família, devido ao medo da rejeição em função da idade associada à instabilidade do relacionamento entre os parceiros. Quando a instabilidade não está relacionada, o principal motivo é a condição socioeconômica precária, visto que a renda familiar não é o suficiente para manter uma gestação e a criação do bebê. Há também motivos relacionados indiretamente com a desinformação quanto aos métodos contraceptivos, pois a falta de esclarecimento sobre o assunto leva muitas adolescentes a engravidarem contra a sua vontade, que, devido à falta de preparo para assumir tal responsabilidade, leva-as a provocar o abortamento.

Entre as formas de indução de aborto observadas durante o estudo estão o uso oral e vaginal de medicamentos como o Cytotec (methotrexate), em proporções iguais às que utilizaram chás e fizeram a introdução de sondas no útero. 
Para prevenir processos de abortamento provocado, é de extrema importância trabalhar com jovens, principalmente adolescentes, mostrando-lhes os riscos e os sentimentos que um ato desse porte causa em uma pessoa. Os danos desse procedimento podem ser tanto físicos como psicológicos.

Este estudo é apenas o primeiro passo de todo um trabalho que pode ser realizado com jovens que passam por uma situação delicada como esta, que deixa sentimentos de culpa, desamparo e medo. É fundamental, para o sucesso de uma equipe multiprofissional de saúde, que dê atenção não somente ao corpo dessas meninas, mas também aos seus sentimentos, servindo de suporte para uma melhor recuperação de sua saúde.

Pela ênfase dada pelas adolescentes aos sentimentos relacionados com o abortamento provocado como fonte de sofrimento, considerase fundamental que nós, da equipe de saúde, repensemos a própria forma de prestar os cuidados de enfermagem às pacientes em abortamento, buscando caminhos para atenuar este sofrimento, como a ampliação do atendimento a adolescentes em escolas, ambulatórios e durante a internação hospitalar.

0 atendimento qualificado aos adolescentes exige atuação interdisciplinar, na qual os saberes dos diferentes profissionais devem ser articulados, não se perdendo de vista o cliente nas suas dimensões biológica, psicológica e social.

\section{Implicações para a Assistência de Enfermagem}

0 desvelamento dos sentimentos das adolescentes que se submeteram ao abortamento provocado faz-nos refletir e sugerir programas de assistência e educação popular:

1. Refletir a prática profissional quanto ao ensino e educação sexual nas escolas de ensino fundamental e graduação em enfermagem;

2. Planejamento familiar: uma parte das responsabilidades da enfermeira de planejamento familiar é aconselhar e orientar os adolescentes sobre os métodos para evitar a gravidez e o reconhecimento do periodo fértil; 
3. Informar sobre as complicações do aborto provocado por pessoas ou profissionais despreparados e em clínicas com más condições de higiene;

4. A enfermeira desempenha uma variedade de papéis importantes no âmbito do planejamento familiar: professora, conselheira, apoiadora e pessoa a quem recorrer. Acima de tudo, ela traz uma compreensão especial e empatia para o cuidado da adolescente; ela compreende a necessidade das adolescentes de controlar sua fertilidade;

5. A enfermeira pode dar ao casal jovem as informações que ele precisa para tomar uma decisão adequada e orientada sobre o controle da natalidade e espaçamento entre o nascimento de seus filhos;

6. Realizar futuras pesquisas que contribuam para melhorar a assistência de enfermagem a mulheres com ou em processo de abortamento e que tragam subsidios para a orientação e educação sexual.

\section{Prevenção dos abortamentos não desejados}

Sem dúvida, são necessárias ações urgentes para aliviar o drama das gestações não desejadas e os abortamentos.

Apesar de a sociedade conhecer os meios para evitar a gravidez e o abortamento não desejado, as questões religiosas e emocionais impedem que essas alternativas sejam postas em prática.

1. A primeira linha de ação é a prevenção do abortamento não desejado através da educação sexual, da prestação de serviços de planejamento familiar e tecnologia contraceptiva de boa qualidade. 2. A segunda linha de ação é a prevenção de complicações e morte de mulheres que abortam, melhorando a assistência e ampliando os conhecimentos da equipe de saúde. 


\section{BIBLIOGRAFIA}

FELIPE, Sonia T. Os direitos em questão na discussão do aborto. In: CAPONI, Gustavo et al. A saúde como desafio ético. Florianópolis: Sociedade de estudos em filosofia e Saúde, 1995.

FONSECA, Adriana Dora da. Assistência de enfermagem a mulheres internadas por complicações associadas ao aborto provocado. Florianópolis ,1996. Dissertação (Mestrado em Assistência de Enfermagem),Universidade Federal de Santa Catarina.

MACED0, Rosa Maria Stefani de, CZERESNIA, Carlos Eduardo., PONTES, Múcio Diniz. Interrupção prematura da gravidez como método anticoncepcional. In: MALBE, HansWolfgang. Tratado de Ginecologia.., 2. ed. São Paulo: Roca, 1993. p. 146-153, p. 709713, p. 928-934.

MINAYO, Maria Cecília de Souza. 0 desafio do conhecimento. Pesquisa qualitativa em saúde. 3. ed. São Paulo - Rio de Janeiro: Hucitec - Abrasco, 1994..

MORETTI, E.; ROVANI, I.M; VARGAS, M.A. Perfil das pacientes com abortamento em setor de emergência. Revista Médica - HSVP Passo Fundo, v.23, p.15-20,Jul.Dez 1998.

PAULA, Wilson Kramer de. Aborto - tradições e contradições. Florianópolis: Papa Livro, 1996.

PINOTTI, J. A Perspectivas médicas sobre as causas e conseqüências de uma gravidez não desejada. SYMPOSIUM INTERNACIONAL “CHISTOPHER TIETZE”, Rio de Janeiro, Brasil, outubro de 1988.

RIBEIRO, Marcos. 0 prazer e o pensar - Orientação sexual para educadores e profissionais de saúde. São Paulo: Gente, 1999. v.1. 
ALAN GUTT MACHER INSTITUTE. Aborto Clandestino: uma realidade latino-americana. New York and Washington. 1994.

VISCOTT, David. A linguagem dos sentimentos. 11. ed. São Paulo: Summus, 1982.

WILLKE, Jack. C.; WILLKE, Sra. Barbara. 0 aborto. 2. ed. São Paulo: Paulinas, 1980. 